\title{
FUTURE LEARNING AND DESIGN CREATIVITY COMPETENCY
}

\author{
Nagai, Yukari (1); Shimogoori, Akio (2); Ariga, Minatsu (1); Georgiev, Georgi V. (3) \\ 1: Japan Advanced Institute of Science and Technology (JAIST), Japan; 2: National Institute of \\ Technology, Hakodate College, Japan; 3: University of Oulu, Finland
}

\begin{abstract}
In this study, we discuss a structure for developing the skills and competencies required by the learning framework of the Organisation for Economic Co-operation and Development (OECD) for future education. Given the broad range of skills and the numerous competencies required to meet the demands of future society, the proposed wider and higher-level framework is based on STEAM (science, technology, engineering, art and design, and mathematics) and addresses the limitations of conventional computational thinking by tackling some of the skills and competencies. This is done by proposing the enrichment of STEAM educational approach with art thinking, which may be defined as a creative human-centred discovery process. To explore such enrichment, we conducted a workshop on art thinking. The motivation of the workshop was to explore whether art thinking can overcome some of the limitations of computational thinking regarding future education in the OECD learning framework. We discuss STEAM as focusing on design creativity competency, and we outline the development of educational activities such as workshops to promote competencies in the perspective of OECD framework.
\end{abstract}

Keywords: Design education, Design process, Creativity, STEAM education, Design creativity

Contact:

Nagai, Yukari

Japan Advanced Institute of Science and Technology (JAIST)

Graduate School of Advanced Science and Technology

Japan

ynagai@jaist.ac.jp

Cite this article: Nagai, Y., Shimogoori, A., Ariga, M., Georgiev, G.V. (2019) 'Future Learning and Design Creativity Competency', in Proceedings of the 22nd International Conference on Engineering Design (ICED19), Delft, The Netherlands, 5-8 August 2019. DOI:10.1017/dsi.2019.54 


\section{INTRODUCTION}

This study elaborates on a case study on the application of art thinking to outline the impact and future directions for contemporary STEAM education as a design creativity competency for applying the OECD learning framework. In this study, we also argue that that a broad range of skills based on STEAM must be consistently developed throughout higher education, including postgraduate education. Contemporary social, environmental, and economic challenges follow an accelerating rate of technological developments. These challenges often require innovative solutions, products, services, and systems. These developments also impose new challenges regarding education and skills to prepare students for the future.

The Organisation for Economic Co-operation and Development (OECD) has outlined its 'Learning Framework for 2030', which focuses on the future of education and skills (OECD, 2018). The goal of the framework is to accelerate education toward a better future through an iterative co-creation and codevelopment process involving multiple stakeholders. In this framework, students need to apply their knowledge in unknown and evolving circumstances in future (OECD, 2018). For this, they will need to acquire and articulate a broad range of skills, including cognitive and meta-cognitive skills (e.g., creative thinking); well-developed social and emotional skills (e.g., empathy); and practical and physical skills (e.g., using new information) (Istance and Kools, 2013). Such a broad range of skills results in a variety of competencies that need to be developed early in school education, connected with educational initiatives such as STEAM (science, technology, engineering, art [art and design], and mathematics).

\section{STEAM COMPETENCY}

\subsection{Adding art and design to STEM}

Traditional STEM (science, technology, engineering, and mathematics) degrees focus on convergent skills, whereas degrees in the liberal arts focus on divergent skills (Land, 2013). Hence, the STEM education concept is elaborates on traditional problem solving approach to innovation. Such innovation is grounded in technology and collaboration (Kärkkäinen and Vincent-Lancrin, 2013). Focusing on this misalignment, the extension of STEM to STEAM (Sousa and Pilecki, 2013) includes art or art and design as a component. The STEAM education can be understood as focused on learning approach elaborating on the five incorporated directions. A wide range of engineering design activities are already essential part of STEAM education (Kim and Park, 2012). STEAM take more holistic view of the world and understand the role of engineering in society, attending to different ethical, environmental, safety and technological concerns.

The inclusion of art or art and design as components creates requirements for how such knowledge and skills need to be taught. Shimogoori, Ariga, and Nagai (2018) reviewed the decisions of an educational council in Japan and considered computational thinking in comparison with the idea of art thinking, further considering the separate impact of these on STEAM education. Both art thinking and computational thinking are essential for STEAM education. These points to the argument that the intersection and elaboration of competencies in STEAM is essential for its application and success in education.

When comparing the art thinking with the design thinking (Jacobs, 2018), there are overlaps in the creative processes of designers and artists. Overall, the art thinking does not necessarily diverge from design thinking. However, compared to the design thinking (Georgiev, 2012), the process of art thinking has a strong emphasis on a few fundamental cognitive strategies (Jacobs, 2018), such as problem-creation, conversation with the work and meta-cognition. We further discuss the strategies of art thinking in Section 3 that introduces the framework of study.

\subsection{OECD learning framework}

The details of the OECD's "Learning Framework for 2030" (OECD, 2018) are shown in Figure 1. The OECD framework intends to promote creativity and critical thought. The framework offers a common vision and principles for the future of education and draws attention to a world situation that is increasingly uncertain, volatile, complex, and ambiguous. 


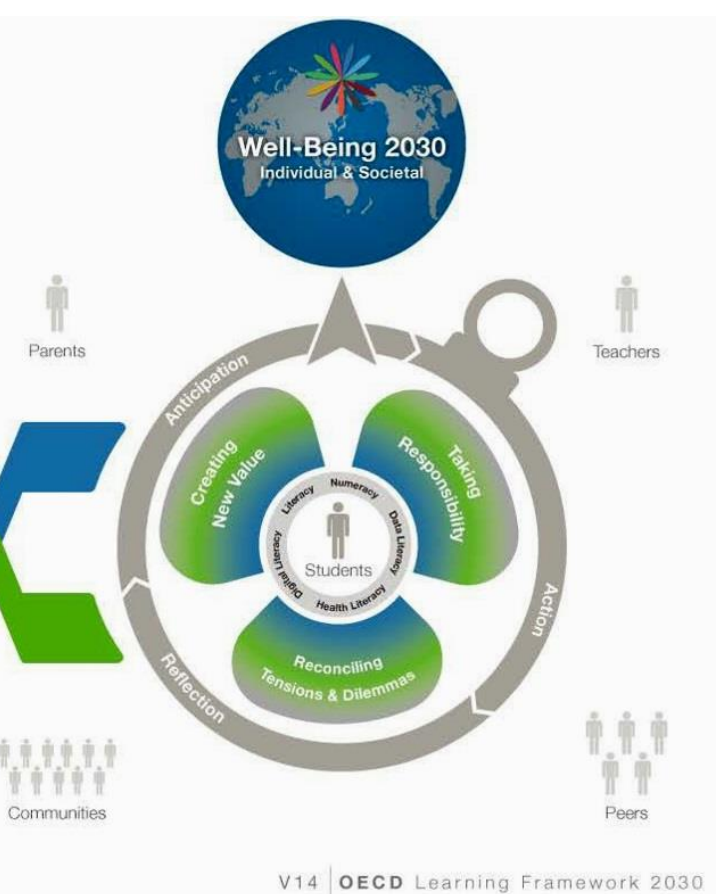

Figure 1. OECD's learning framework for 2030 (based on OECD, 2018)

Confronted with environmental, economic, and social disruption challenges, it asks how educational systems can "develop the knowledge, skills, attitudes and values that today's students need to thrive and shape their world effectively" (OECD, 2018). The need for a broad set of knowledge, skills, attitudes, and values in action are highlighted.

The concept of competency implies more than just the acquisition of knowledge and skills; it involves the mobilization of knowledge, skills, attitudes, and values to meet complex demands. Future-ready students will need both broad and specialized knowledge.

As already outlined, students will need to apply their knowledge in unknown and evolving circumstances, needing:

- Cognitive and meta-cognitive skills, such as critical thinking, creative thinking, learning to learn and self-regulation;

- Social and emotional skills, such as empathy, self-efficacy, and collaboration; and

- Practical and physical skills, such as using new information and communication technology devices.

Furthermore, the framework covers three aspects of the education of students (Figure 1):

- Creating new values, which is understood as the ability to produce new products and services, and new social models in cooperation with others, including adaptability, creativity, curiosity, and an open mind for accepting others.

- Reconciling tensions and dilemmas, which is understood as the ability to balance various competing demands, such as equality and freedom, needs of individuality vs. the needs of the community or of society, and change and continuity.

- Taking responsibility, which is understood as the ability to consider the future outcome of one's actions, the ability to responsibly explain the outcome of one's work, and the ability to evaluate on one's own. It includes the feeling of self-efficacy, a sense of responsibility, the ability to solve problems, adaptability, etc.

These aspects stem from students' numeracy, data literacy, health literacy, digital literacy, and literacy in general.

CDIO or Conceive, Design, Implement, and Operate Systems in the Enterprise, Societal and Environmental Context (Crawley et al., 2011; Gaidi, 2003) is an educational framework or model that is aimed at undergraduate engineering education. The CDIO does not necessarily diverge from the OECD learning framework, particularly in the CDIO categories of "Personal And Professional Skills And Attributes" and "Conceiving, Designing, Implementing, And Operating Systems In The Enterprise, Societal And Environmental Context" (Crawley et al., 2011). However, towards knowledge and skills to be applied in unknown and evolving circumstances, OECD learning 
framework provides more fundamental need categories of Knowledge, Skills, and Attitudes and Values and their sub-categories (Figure 1).

\subsection{Design creativity competency}

Creativity has long been articulated as a core expertise of designers (Conley, 2004). Moreover, design creativity is a key competency to be incorporated in the design curriculum (Acuna and Sosa, 2010), as it has a direct impact on innovation potential. Various methods and tools are considered to be applicable approaches for fostering the creative competencies of both individuals and teams in relation to design (Nagai and Taura 2016, Nagai 2015).

The competency of design creativity, that is, the ability to do design creativity in a successful and effective way, encompasses a wide range of knowledge, skills, and attitudes and values. Building competency for design creativity require the development of such knowledge, skills, and attitudes and values.

Previous studies note the specific skills and knowledge that can be seen as part of design creativity competency, such as the ability to frame the problem, knowledge of the domain, and making novel arrangements of established knowledge items (Editorial Board of IJDCI, 2013).

The overreaching question is how to transform the process from teaching future creative designers to teaching them to develop design creativity as competency, in the context of the framework and the challenges we face in future (OECD, 2018). Next, we will discuss the framework to answer this question.

\section{FRAMEWORK OF THIS STUDY}

\subsection{Addressing limitations of computational thinking in STEAM}

Computational thinking studies the problem at hand comprehensively and approaches the problem through logical thinking. STEAM learning and competencies, however, currently incorporate computational thinking and art (or art and design) competencies, relying on defined problems and based on logical thinking. Computational thinking can teach many of the competencies in STEAM, but the competencies that cannot be taught by computational thinking limit the model's effectiveness. These limitations can be addressed by art thinking.

The key difference between computational thinking and art thinking is in the way of approaching the problem. Computational thinking proceeds in problem solving by using logical thinking, reading the problem in a way similar to coding programs, instead of reading the problem in the context of society and the real world. Art thinking presents a new meaning to the gap between the individual (personal) and the world by communicating and noticing the intrapersonal dimension. Therefore, approaching the problem in computational thinking is matching the real world and society. However, art thinking is not only matches the real world and society but also affirms the gap and bridges it. Therefore, art thinking has a role in addressing the limitations of computational thinking by motivating art-related creative development.

\subsection{Art thinking in STEAM}

Art thinking occurs in a mind that imagines and realizes a future (Akiyama et al., 2015), and an ability to creatively bridge the gap between social and personal thought (Murayama et al., 2015). Art thinking includes altruism and a mind that imagines and realizes a future (Figure 2).

Take the case of a workshop on art thinking. The motivation of the workshop is to explore whether art thinking can overcome some of the limitations of computational thinking regarding future education in the OECD learning framework.

Art thinking gives new meaning to the gap between the personal and the world by communicating and noticing the intrapersonal dimension. Compared to computational thinking, art thinking is not only matching the real world and the society but affirms and solves the gap.

\subsection{STEAM as design creativity competency}

Incorporating art thinking as a method to overcome the limitations of computational thinking in providing competencies, this study discusses STEAM as a design creativity competency. 


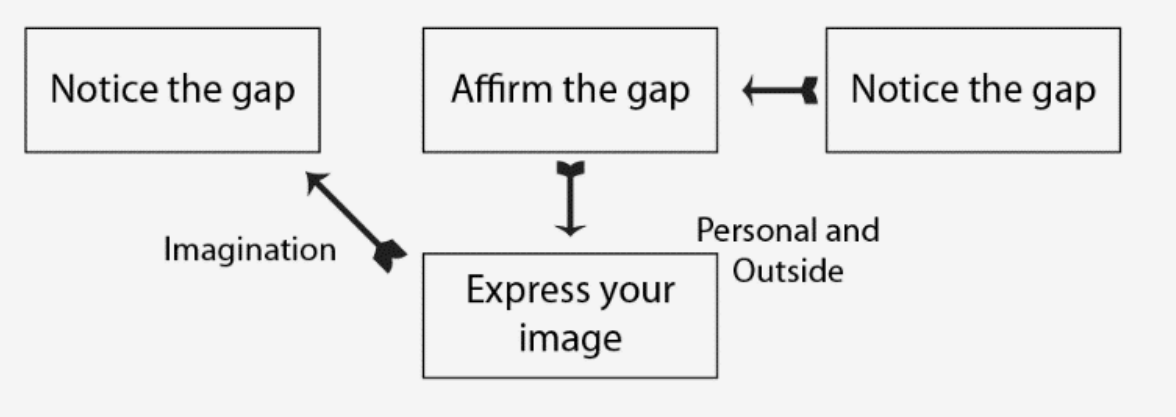

Figure 2. Creative process in art thinking (Murayama, Ariga and Sakai, 2015)

Table 1. Eight intelligences in the multiple intelligences theory

\begin{tabular}{|c|c|c|}
\hline & Intelligence & Description \\
\hline 1 & $\begin{array}{l}\text { Verbal- } \\
\text { linguistic }\end{array}$ & $\begin{array}{r}\text { An ability to learn, communicate, write, read, and } \\
\text { use language. }\end{array}$ \\
\hline 2 & $\begin{array}{l}\text { Logical- } \\
\text { mathematical }\end{array}$ & $\begin{array}{r}\text { Analyse problems, manage numbers in a } \\
\text { mathematical way, and solve problems in a } \\
\text { scientific way. }\end{array}$ \\
\hline 3 & $\begin{array}{l}\text { Musical- } \\
\text { rhythmic }\end{array}$ & $\begin{array}{r}\text { An ability to play musical instruments or compose } \\
\text { songs. }\end{array}$ \\
\hline 4 & $\begin{array}{l}\text { Bodily- } \\
\text { kinaesthetic }\end{array}$ & Create and solve problems by using the body. \\
\hline 5 & Visual-spatial & $\begin{array}{r}\text { Analyse, manage, and recognize patterns in spatial } \\
\text { terms. }\end{array}$ \\
\hline 6 & Interpersonal & $\begin{array}{r}\begin{array}{r}\text { Understand other people and maintain good } \\
\text { relations between them. }\end{array} \\
\end{array}$ \\
\hline 7 & Intrapersonal & $\begin{array}{r}\text { Control yourself and understand yourself so you } \\
\text { can live in an effective way. }\end{array}$ \\
\hline 8 & Naturalistic & $\begin{array}{r}\text { Recognize categories of phenomena and } \\
\text { understand different species. }\end{array}$ \\
\hline
\end{tabular}

Competencies that can be built with art-thinking-enriched STEAM education include:

- Competencies contributing to creating new values, and

- Competencies contributing to reconciling tensions and dilemmas.

STEAM competencies enrich the ability to build the competency requirements of design creativity in terms of overcoming the limitations of computational thinking.

This study explores the possibilities of art thinking to address the perceived limitations of computational thinking in STEAM. We will now discuss a broader framework to STEAM as design creativity competency and will outline directions for the development of educational activities such as workshops to develop competencies in the perspective of the OECD framework.

We see the design creativity competency as developed throughout the various educations stages. The proposed wider and higher-level framework, based on STEAM, addresses the limitations of conventional approaches by tackling some specific skills and competencies. This is done by proposing the enrichment of STEAM educational approach with art thinking, which may be defined as a creative human-centred discovery process that requires to be developed throughout the various educations stages.

\section{THE CASE OF A WORKSHOP ON ART THINKING}

This case discusses a workshop that delivers the essence of art thinking to stimulate the development of in terms of the participants' multiple intelligences (MI) (Shimogoori, Ariga, and Nagai, 2018). The workshop on art thinking applies the framework of the creative process in art thinking (Figure 2; see Murayama, Ariga and Sakai, (2015)). To investigate the differences in the participants' perceptions, the results of the workshop were analysed using the MI theory of H. Gardner (Table 1 (Gardner, 1983; 2008)). 
The workshop investigates the transformation and the change in the emotion of the participants from step (2), 'Affirm the gap', to step (3), 'Express your image' (see Figure 2).

The workshop, 'Become a Friend with a Sleepy Bear', was delivered to 62 elementary school students (all ten years old) in Japan. This children's task in the workshop was to come up with a friend for the character from a well-known picture book. In detail, the children are given an illustration of the bear. Using the prepared materials, children decorate the bear and give a description of his or her physical characteristics.

The brief was presented to the participants with consideration of the connection of story and the characters (focused on logical-mathematical, verbal-linguistic intelligences). The instruction included: (1) Imagine the traits of the character, provide a chance to think about its originality (focused on intrapersonal intelligence); and (2) Share the completed work with friends (focused on intrapersonal intelligence).

The MI was investigated on the basis of self-evaluations before and after the workshop. An analysis of the results applying MI frameworks show that the students demonstrated improvement in all kinds of intelligences, except for interpersonal intelligence. In his work, Gardner claims that if all eight intelligences are focused on achieving artistic goals, then there is a possibility that all the intelligences could be improved. The present research results agree with Gardner's claim (Gardner, 1983). Speaking within the concept of art thinking, it seems that if the individual's self-esteem is actively functioning, then one develops an intelligence that is necessary when art thinking moves to step (3), 'Express your image', from step (2), "Affirm the gap" (see Figures 3 and 4).

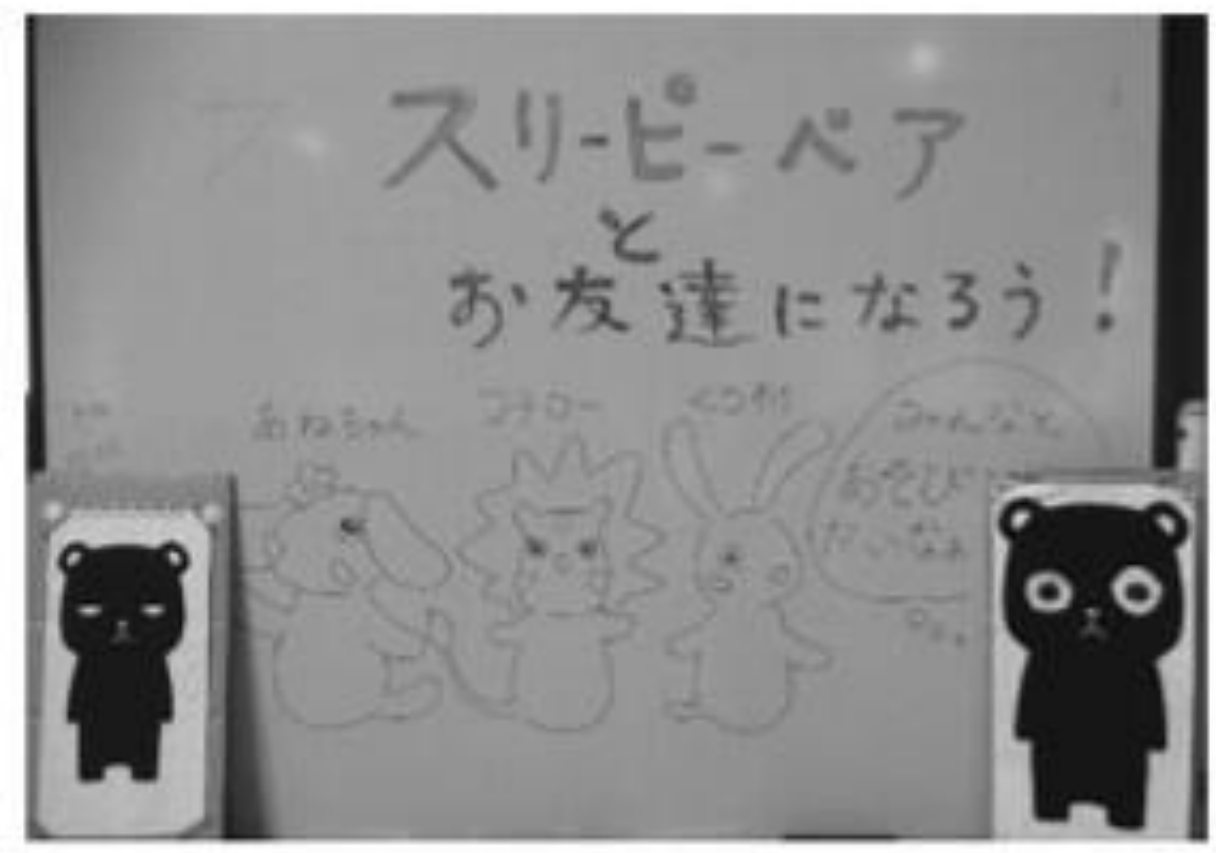

Figure 3. Example explanation of the designed character from the workshop (Shimogoori, Ariga, and Nagai, 2018)

To affirm such movement, the workshop had the students perform tasks to test the multiple intelligences as below.

- Consider the connection of story and the characters (tests logical-mathematical and verballinguistic intelligence).

- Imagine the traits of the character and provide a chance to think about its originality (tests intrapersonal intelligence).

- $\quad$ Share the completed work with friends (tests interpersonal intelligence). 

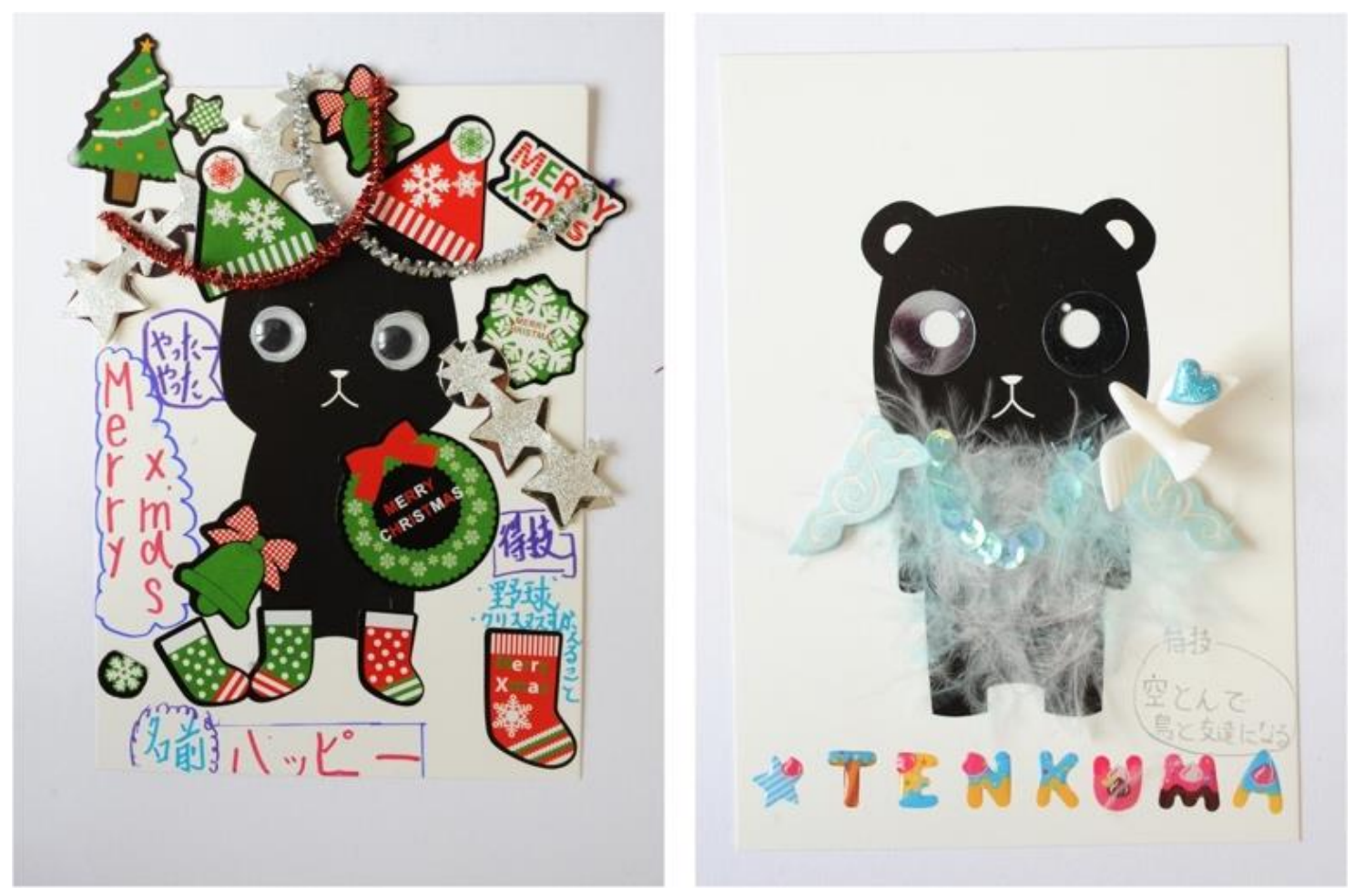

Figure 4. Two examples of the students' work

With this educational intention, the other intelligences are developed accordingly. Each learning process has a choice of method (Kamijou, 2003): (1) the aesthetic, (2) the narrative, (3) the logical/quantitative, (4) the foundational, and (5) the experiential.

The result tested multiple intelligences before and after the workshop and showed that differences among individuals in how they understand others rely on a positive relationship with society, especially when it involves communication through words.

The results of the multiple intelligences self-reported evaluations before and after the workshop shows notable improvements in five out of eight of the intelligences (verbal-linguistic, musical-rhythmic, bodily-kinaesthetic, visual-spatial, and interpersonal, circled in Figure 5). Self-reported evaluations use scale from 1 (low) to 5 (high).

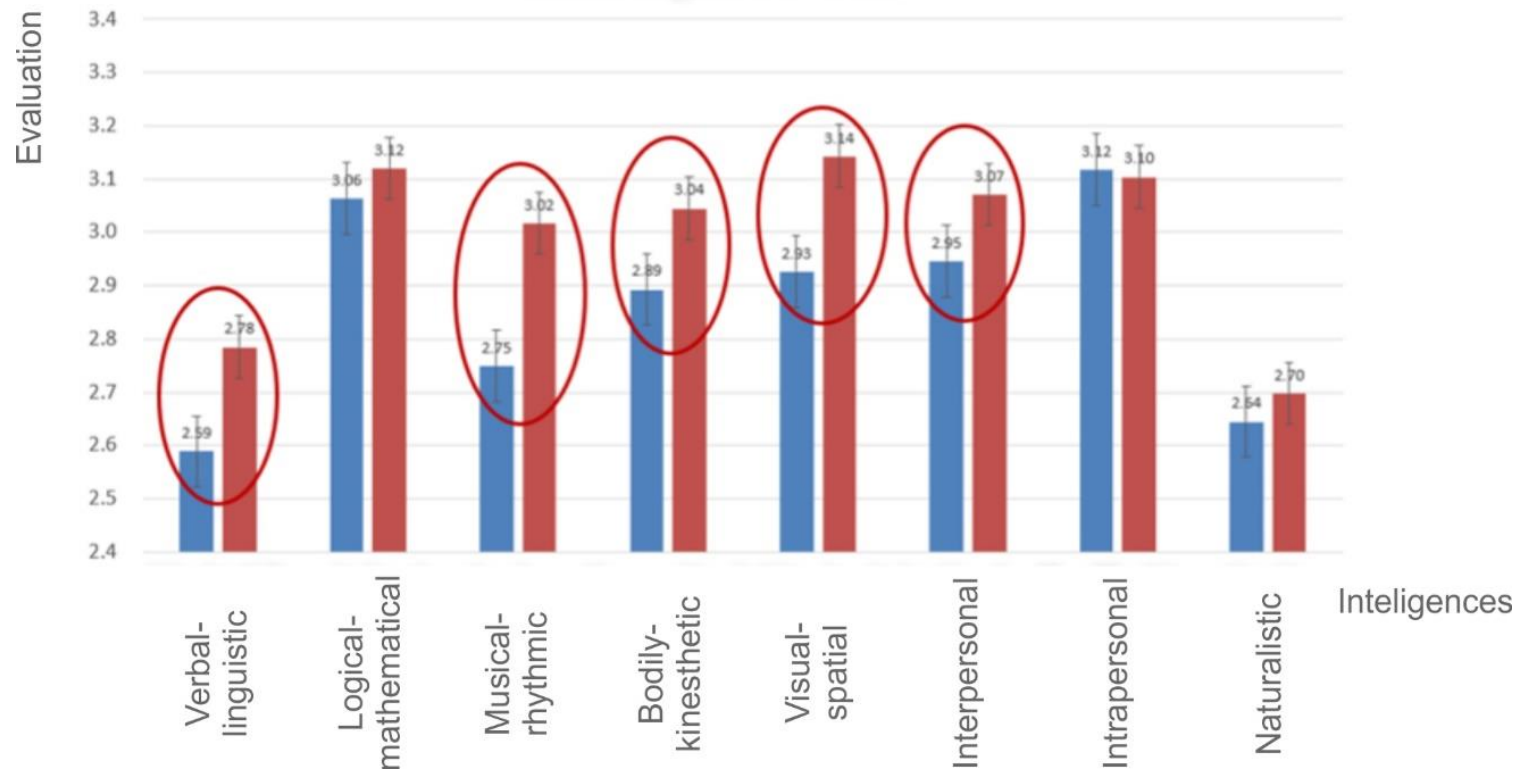

Figure 5. Eight intelligences evaluations before and after the workshop 


\section{DISCUSSION}

The case above discusses the introduction of a workshop on art thinking into educational environments that previously focused on traditional computational thinking. The results of the workshop indicate that the application of art thinking is possible to address a broad range of multiple intelligences. These may reflect the development of corresponding skills and competencies.

By contrast, more traditional approaches to STEAM education do not deliberately address art thinking with its approach of finding the problem and treating the gap between social and personal thought. Such traditional approaches to STEAM education result in only some of the students being able to produce results in line with art thinking (Sánchez Milara et al., 2017).

According to the results of our case study, if all eight of the intelligences are focused on achieving artistic goals, then all the intelligences can be improved. The workshop may stimulate the development of participants' multiple intelligences.

To address the perceived issues in traditional approaches to STEAM, we propose that the workshop should focus both on art and design thinking:

- It should include activities on the generation of creative ideas, solutions, products, or services, based on particular seeds.

- It should articulate art thinking in the context of computational thinking.

- It should be aimed at activating/stimulating multiple intelligences.

The following are particular approaches to address OECD framework (OECD, 2018) in smaller educational initiatives such as workshops, or larger educational initiatives classes and programs:

- Addressing the "taking responsibility" aspect by developing skills and competencies for design creativity such as question-asking, framing, systematizing, listening, visualizing, globalizing, abstracting, and investigating.

- Addressing the "reconciling tensions and dilemmas" aspect by developing skills and competencies for design creativity such as interviewing, discussing, listening, empathizing, teamwork, discussing, and mediating.

- Addressing the "creating new value" aspect by developing skills and competencies for design creativity such as motivating, imaging, feeling, goal-setting, storytelling, interviewing, playing, empathizing, building, testing, interacting, hands-on learning, sketching, visualizing, and prototyping.

Further, we outlined the eight multiple intelligences in the context of design creativity as authors' interpretation in the perspective of the workshop results (Table 2). The intelligences can be translated into skills and competencies for design creativity, such as hands-on learning skill/competency for the bodily-kinaesthetic intelligence.

Table 2. Authors' interpretations of the eight intelligences in the context of skills and competencies for design creativity

\begin{tabular}{|c|c|c|}
\hline & Intelligence & Interpretations \\
\hline 1 & $\begin{array}{l}\text { Verbal- } \\
\text { linguistic }\end{array}$ & $\begin{array}{r}\text { Storytelling, interviewing, discussing, playing, } \\
\text { empathizing }\end{array}$ \\
\hline 2 & $\begin{array}{c}\text { Logical- } \\
\text { mathematical }\end{array}$ & Question-asking, framing, systematizing \\
\hline 3 & $\begin{array}{l}\text { Musical- } \\
\text { rhythmic }\end{array}$ & Listening \\
\hline 4 & $\begin{array}{c}\text { Bodily- } \\
\text { kinaesthetic }\end{array}$ & Building, testing, interacting, hands-on learning \\
\hline 5 & Visual-spatial & Sketching, visualizing, prototyping \\
\hline 6 & Interpersonal & Teamwork, discussing, mediating, empathizing \\
\hline 7 & Intrapersonal & $\begin{array}{r}\text { Motivating (motivation), imaging, feeling, goal } \\
\text { setting }\end{array}$ \\
\hline 8 & Naturalistic & Globalizing, abstracting, investigating \\
\hline
\end{tabular}

Using this framework for incorporating art thinking STEAM education and developing overall design creativity competency, we can develop a broad range of necessary skills and competencies for future learning, as outlined in the OECD framework (2018). 
The present study has the limitations of using single workshop to investigate the changes in the eight MI areas and using self-evaluations to evaluate these changes. Further work should address these limitations by comparing two design tasks with and without application of art thinking approach.

\section{CONCLUSIONS}

Given the broad range of skills and a range of competencies required to meet the demands of society in the future, in this study we discussed a framework to develop such skills and competencies. The framework is based on STEAM and addresses the limitations of conventional computational thinking in addressing some of the skills and competencies required by the OECD learning framework (2018) for future education. We have done this by proposing to enrich STEAM with art thinking. Such a wider framework also targets educational initiatives various levels, from early school education to postgraduate education and must therefore be developed consistently through the various education stages. We discussed STEAM as overall design creativity competency, and we outlined directions of developing educational activities such as workshops to develop competencies, in addition to those of science and engineering, in the perspective of the OECD framework.

\section{REFERENCES}

Acuna, A. and Sosa, R. (2010), "The complementary role of representations in design creativity: Sketches and models", in Taura, T. and Nagai, Y. eds., Design Creativity, Springer Science \& Business Media, pp. 265270. https://doi.org/10.1007/978-0-85729-224-7

Akiyama, Y., M. Ariga and K. Sakai (2015), "Create New Business by Art Thinking” (in Japanese), in Japan Association for Communication 12th Annual Meeting, pp. 60-69.

Armstrong, T. (2009), "Multiple Intelligences in the Classroom”. Third Edition, AECD, Alexandria, VA.

Crawley, E. F., Malmqvist, J., Lucas, W. A. and Brodeur, D. R. (2011), "The CDIO syllabus v2.0. An updated statement of goals for engineering education", In Proceedings of 7th International CDIO Conference, Copenhagen, Denmark, June p. 20-23.

Editorial Board of IJDCI (2013), "Perspectives on design creativity and innovation research", International Journal of Design Creativity and Innovation, Vol. 1 No. 1, pp. 1-42. https://doi.org/10.1080/21650349.2013.754657

Gaidi, K. E. (2003). "Reforming engineering education: The CDIO initiative". Industry and Higher Education, Vol. 17, No. 6, pp. 431-434.

Gardner, H. (2008), Multiple Intelligences: New Horizons in Theory and Practice. Basic Books, New York.

Gardner, H. (1983), Frames of Mind: The Theory of Multiple Intelligences. Basic Books, New York.

Georgiev, G.V. (2012), "Design Thinking: An overview", Design Thinking - Special Issue of Japanese Society for the Science of Design, Vol. 20-1 No. 77, pp. 70-77.

Istance, D. and Kools, M. (2013), "OECD work on technology and education: Innovative learning environments as an integrating framework", European Journal of Education, Vol. 48 No. 1, pp. 43-57.

Jacobs, J. (2018), "Intersections in Design Thinking and Art Thinking: Towards Interdisciplinary Innovation". Creativity. Theories-Research-Applications, Vol. 5 No. 1, pp. 4-25. https://doi.org/10.1515/ctra-2018-0001

Kärkkäinen, K. and Vincent-Lancrin, S. (2013), "Sparking Innovation in STEM Education with Technology and Collaboration a case study of the HP catalyst initiative" http://www.oecd.org/education/ceri/OECD_EDUWKP\%282013\%29_\%20Sparking\%20Innovation\%20in\%20STEM\%20education.pdf accessed 07 Dec 2018

Kim, Y. and Park, N. (2012), "The effect of STEAM education on elementary school student's creativity improvement". In Computer applications for security, control and system engineering. Springer, Berlin, Heidelberg, (pp. 115-121).

Land, M.H. (2013), "Full STEAM ahead: The benefits of integrating the arts into STEM", Procedia Computer Science, Vol. 20, pp. 547-552. https://doi.org/10.1016/j.procs.2013.09.317

Murayama, M., Ariga, M. and Sakai, K. (2015), "Zest for living: Art thinking” (in Japanese), in Japan Association for Communication 15th Annual Meeting, pp. 17-20.

Nagai, Y. (2015), "A sense of design: The embedded motives of nature, culture, and future", In Principia Designae-Pre-Design, Design, and Post-Design. Springer, Tokyo, (pp. 43-59). https://doi.org/10.1007/978-4-431-54403-6_4

Nagai, Y. and Taura, T. (2016), "Studies of design creativity: A review and its prospects", Journal of the Indian Institute of Science, Vol. 95, No. 4, pp. 341-351.

OECD (2018), "Learning Framework for 2030: The future of education and skills", In Education 2030-The Future We Want. Organisation for Economic Cooperation and Development Indicators, Paris https://www.oecd.org/education/2030/E2030\%20Position\%20Paper\%20(05.04.2018).pdf accessed 07 Dec 2018 
Sánchez Milara, I., Georgiev, G.V., Riekki, J., Ylioja, J. and Pyykkönen, M. (2017), "Human and technological dimensions of making in FabLab", The Design Journal, Vol, 20 No. sup1, pp. S1080-S1092. https://doi.org/10.1080/14606925.2017.1353052

Sousa, D.A. and Pilecki, T. (2013), From STEM to STEAM: Using Brain-compatible Strategies to Integrate the Arts. Corwin Press, SAGE Publications. 